\title{
Kentlerin Türkiyesi: İmkânlar, Sınırlar ve Çatışmalar
}

\author{
Rümeysanur Erikli Doğan 1 \\ ORCID: 0000-0003-0903-9078
}

Genç, F., Keyder, Ç., Keyman, E. F., ve Badur, A. K. (2021)

Kentlerin Türkiyesi: İmkânlar, Sınırlar ve Çatışmalar

İletişim Yayıncılık (2021)

\section{Giriş}

Bu kitap ekonomik küreselleşmenin Anadolu kentlerindeki etkisini “kentbölge" kavramını merkeze alarak incelemektedir. Yazarlar 2017 yılında TÜRKONFED için hazırladıkları "Kent Bölge-Yerel Kalkınmada Yeni Dinamikler: Türkiye'nin Kentlerinden Kentlerin Türkiye'sine" başlıklı çalışmadaki on iki kentten dördüne odaklanarak ve rapora ek olarak küreselleşme ve kent literatürleriyle önemli bağlar kurarak bu kitabı hazırlamışlardır (Keyman, Keyder, Genç ve Köse, 2017). ${ }^{2}$ Bu yazıda öncelikle kitabın amacını, genel çerçevesini şekillendiren kavramları ve üzerine inşa olunduğu literatürü analiz edeceğim. Akabinde kitabın teorik çerçevesinin İzmir, Adana-Mersin ${ }^{3}$, Konya ve Van vaka incelemelerindeki sonuçlarını paylaşacağım. Yazarlar sadece İzmir'in bir kent-bölge olduğunu ve diğer kentlerin ise kent-bölge olma potansiyeli barındırdığı belirtmiştir. Analiz edilen tüm kentler için kent-bölge olma yolundaki imkânları ve kısıtları politika önerisi olarak sıralamıştır. Kitap, kır ve kent zıtlığı üzerine kurulmuş olan kent kavramının sınırlarını aşmaya çalişan kent bölge kavramını, Türkiye'de teorik ve ampirik olarak test ederek hem Türkiye kentlerini çalışanlar için bu kavramın kent çalışmaları için getir-

\footnotetext{
${ }^{1}$ Marmara Üniversitesi, Sosyoloji, Doktora Adayı

2 İlgili raporun tamamına linkten ulaşabilirsiniz: https://turkonfed.org/Files/ContentFile/turkiyenin-kentlerinden-kentlerin-turkiyesine.pdf

${ }^{3}$ Adana ve Mersin'in beraber bir kent bölge oluşturma potansiyeline sahip olduğu düşünüldüğü için hep bir arada ele alınmıştır. (Genç, Keyder, Keyman ve Badur, 2021, s. 137-164).
} 
diği firsatları ve sınırları göstermektedir hem de bu konudaki dünya akademisindeki tartışmalara Türkiye kentlerinin dahil olmasına saha çalışmalarryla önemli bir katkı sağlamıştır.

\section{Genel Çerçeve ve Eleştirel Kent-Bölge Yaklaşımı}

Kitabın amacı, 2000 ve sonrasında ekonomik küreselleşmenin Anadolu kentlerini nasıl etkilediğini incelemek ve kent-bölge literatürünü Türkiye bağlamında yeniden değerlendirmektir. Küreselleşmenin Anadolu kentlerindeki etkisinin izini sürmek için o kentin ekonomisindeki dönüşümün (i) kentin ülke genelindeki rolünü, (ii) sınıf içi ve sınıflar arası çatışmaları ve (iii) kentsel koalisyonların yapısını ve nüfuzunu nasıl etkilediğine bakarlar.

Küreselleşme ve kent-bölge ilişkisini değerlendirirken burada İstanbul ve Ankara gibi daha ön planda olan Türkiye kentleri yerine İzmir, Adana-Mersin, Konya ve Van kentleri birkaç sebepten ötürü seçilmiştir. Öncelikle Şerif Mardin'in (1973) merkez-çevre teorisi göz önüne alınarak, İstanbul ve Ankara merkez kentler olarak düşünülmüş ve bunlara odaklanmak yerine sayılan dört çevre kentlere odaklanmanın küreselleşmenin Türkiye'de göz ardı edilen etkisini açığa çıkarması hedeflenmiştir (Genç, Keyman, Keyder ve Badur, 2021, s.11). Bu teorik imkân arayışına ek olarak Anadolu kentlerinde son yirmi yıldır demografi verilerine yansıyan bazı değişimler (İstanbul'a göç azalırken, bazı Anadolu kentlerine artması, bazı kentlerin birbirine eklemlenmesi gibi) de analizin buraya çevrilmesini gerekli kılmıştır. Son olarak ekonomik küreselleşmenin mekânsal formu olan kent-bölgenin Anadolu kentlerinde oluşturduğu özgül yapının incelenmesi amaçlanmıştır. Her ne kadar yazarlar merkez-çevre ikiliğini kabul etse de kent-bölge çalışmalarında küresel kentler haricindeki kentlerin analiz edilmesi bu eski ikiliğin aşılması için bir imkân olarak görülmüştür (Neuman ve Hall, 2009, s. 781). Ayrıca Scott'a göre (2000, s. 2) kapitalizmin coğrafi birimi kent-bölgelerdir ve doğru bir analiz için bu eski ikiliklerin aşılması gerekir.

Seçilen Anadolu kentleri küreselleşme, kent-bölge ve yerelleşme olmak üzere üçlü kavramsal sacayağı üzerinden incelenmiştir. Bu bölümde yazarların sırasıyla bu kavramlara literatürle ilişki kurarak yükledikleri anlamları inceleyeceğim. Burada amacım yazarların kurduğu eleştirel kent-bölge teorisinin köklerini görünür kılmak ve kitabın teorik temellerini tartışmaya açmak. 


\section{Küreselleşme}

Kitaptaki küreselleşme yaklaşımı, neoklasik bakış açısı ve yapısalcı Marksist eleştirilerin dışında bir üçüncü yol yaklaşımı olarak düşünülebilir. Çünkü küreselleşmeye, tepeden inen bir süreç olarak değil yerel ve küreselin birbiriyle mücadelesinde şekillenen ve ekonomik ya da teknolojik değişim yerine politik olarak inşa edilen bir süreç olarak yaklaşmışlardır (Genç vd., 2021, s. 12). Küreselleşmenin bu şekilde bir politik inşa süreci olarak görülmesi hem yerel yönetişim literatürünün ve bu kentlerdeki pratiklerinin incelenmesini hem de merkezin yatırım ve yönetim açlarından yerele müdahalesinin etkilerinin gözlemlenmesini sağlamıştır. Daha somut ifade etmek gerekirse bir yandan AKP'den farklı bir partinin belediyeye seçilmesinin ve bunun yereldeki koalisyonlara ve yatırımlara yansıması incelenirken (İzmir, Van ve Adana Mersin aksı) diğer yandan AKP'nin seçilmesinin ve bununla bütünleşik bir kentsel koalisyonun kurulmasının yereldeki (Konya) sonuçlarına bakılmıştır.

Buna ek olarak yazarlar küreselleşmeyi ulus devleti yok eden bir süreç olarak görmek yerine, 1970 sonrasında küresel sermayenin girdiği krizle "daha önce ulusal ölçekte örgütlenmiş kapitalist üretim, tüketim ve dolaşım ilişkilerinin ulus üstü ölçekte yeniden yapılanması (rescaling)" (Genç vd., 2021, s. 13) süreci olarak görürler. Bu bağlamda "kent-bölge" kavramı bu sürecin hem mekânsal sonucu hem de küreselleşmeyle ilişkilenmenin aracı olmuştur (a.g.e., s. 45).

\section{Kent-bölge}

Kent-bölge kavramının tarihsel olarak kökeni, 1980lerde kentlerin etki alanlarının idari sınırları aşacak kadar geniş olmaya başlamasında ve kentin ayak izlerinin kırda devam etmesinde yatmaktadır (Tekeli, 2016, s. 143-158). Yazarların eleştirel yaklaşarak kabul ettiği Yeni Bölgecilik akımı, kent-bölgeleri küresel ekonomide kentler için kalkınmayı gerçekleştiren aktörler olarak görmüştür (Genç vd., 2021, s. 38-39). Coğrafyanın sonu iddialarına karşı eleştiri olarak yükselen bu akıma göre küresel dünyada kentlerin yaratıcı ve yenilikçi olması onları başarılı kılar ve bu başarılarının ardındaki etmenler de yer bağımlıdır.

Kentlerin Türkiyesi kitabının Yeni Bölgecilik akımından en çok beslendiği yer "yı̆̆ılma (agglomeration)" kavramıdır. Bu kavramının kent-bölgeyle ilişkisini açıklayan önemli kuramcılardan biri olan Scott'a göre bir yandan iletişim ve ulaşım teknolojileri bazı sektörlerin yüz yüze iletişime geçmeden işlerini yürütmelerini sağlasa da ekonominin birçok önemli segmentinin birbirine yakın olması gerekir (2000, s.7). Bu yakınlığı ve biraradalığı tanımlamak için 
“yığılma” kavramı kullanılır (a.g.e., s. 8). Her ne kadar Kentlerin Türkiyesi kitabında yığılma kavramıyla onun ürettiği pozitif dışsallıklar eş anlamlı kullanılsa da Scott'a göre yı̆̆glmalar negatif dışsallıklar da üretir (a.g.e., s. 7; Genç vd., 2021 s. 40).

Yazarlar, Yeni Bölgecilik akımına yöneltilen ekonomik indirgemecilik ve Avrupa Merkeziyetçi olma eleştirilerini kabul eder (Genç vd., 2021, s. 44-48). Bu eleştirilere göre kent-bölge kavramı şeyleştirilmiştir çünkü kent-bölgenin kendisinin ekonomik gelişme ve innovasyonu getireceği düşünülmüştür. Oysa yazarlara göre kent-bölge küreselleşmenin zorunlu bir sonucu değil küresel, ulusal ve yerel ölçeklerde çeşitli aktörlerin mücadelesi sonucunda biçimlenen siyasal bir süreçtir. Yazarlar ayrıca Yeni Bölgecilik akımının batı merkezli olduğu eleştirisine katılsa da batı dışının tamamen özgün yapılar ürettiğini savunan tikelci pozisyona düşmek istemezler (a.g.e., s. 47-48). Türkiye'deki kent-bölge oluşumun Avrupa' dakinden en önemli farkı sanayisizleşme tecrübesinde yatmaktadır. Sanayisizleşme Batı'da sanayinin çevre ülkeler taşınması, mavi yakalıların nüfustaki oranın azalması ve kentlerde finans, yazılım ve teknoloji gibi hizmet sektörlerinin ağırlık kazanması süreci olarak yaşanmıştır. Türkiye' de ise sanayi 1980 sonrasında İstanbul'un kent merkezinden Çerkezköy ve Gebze gibi çeperlere ve Bursa, Eskişehir, Konya, Gaziantep ve Denizli gibi Anadolu kentlerine taşınmıştır (a.g.e., s.64-66).

\section{Yerelleşme}

Dewer ve Epstein'a göre bölgenin üç farklı mekânsal tanımı yapılabilir: bağlantı (linkage), gradyen ve sinırları belli alan (bounded) (Dewer ve Epstein dan aktaran Neuman ve Hull, 2009, s. 778-779). Kentlerin Türkiye'si kitabında bölge mekânsal olarak bir akışlar ya da bağlantılar mekânı olarak değil sınırları belirli bir alan olarak tahayyül edilmiş ve bunun paralelinde işaret ettikleri s1nırlı alandaki politikalara ve yerel koalisyon gruplarına odaklanılmış.

Kitaptaki yerelleşme yaklaşımını bir yerel demokrasi projesi olarak tanımlayabiliriz çünkü kentlerin ekonomik gelişimini önceleyen kentsel büyüme koalisyonlarının demokratik, eşitlikçi ve kapsayıcı bir siyasal ve ekonomik hayatın kurulmasında kilit bir role sahip olduğu ön görülmüş̧ür (Genç vd., 2021, s. 22). Bu nedenle neoliberal ve otoriter popülizmin şekillendirdiği “Türkiye'nin Kentleri” yerine bu şekilde yerelden filizlenen ve kentlerin ekonomik gelişimini sağlayacak bir "Kentlerin Türkiye'si" yaklaşımının benimsenmesi gerektiği savunulmuştur.

Bu savların arkasındaki teorik yapı Yeni Kurumsalcı Sentez'e ve pratik bir merkezileşme eleştirisine dayanmaktadır. Buna göre kalkınma tepeden inmeci 
Keynesçi ya da neoliberal yaklaşımlarla gerçekleştirilemez. Bunun yerine yereldeki karşılıklı ilişkileri gözeten, yerelin potansiyelini öne çıkaran ve yerelden inşa edilen bir süreç olması gerekir (Ash Amin'den aktaran Genç vd., 2021, s.41). Ayrıca merkezileşmenin toplumsal kutuplaşma ve çatışmayı arttırdığı ve yerele karşı güven kaybına neden olduğu aktarılmıştır. (a.g.e., s.226).

\section{Vakalar}

Kitapta vaka analizlerine, kent-bölge olma potansiyelini gerçekleştirmiş tek kent olan İzmir ile başlanır. İzmir'in Manisa ile bir bölge oluşturduğu düşünülmüş ve bu bölge küreselleşmenin çelişkilerini açığa çıkaran bir alan olduğu için seçilmiştir (Genç vd., 2021, s.108). Yazarların küreselleşmeyi politik inşa olarak düşünmesi bölgedeki farklı kalkınma bakış açılarına sahip üç ayrı koalisyonun (i. İzmir Büyükşehir Belediyesi, girişimci dernekler ve odalar, ii. Merkezi hükümetin nüfuzunu sağlayan İzmir Kalkınma Ajansı ve valilik, 3. Büyüme karşıtı koalisyonu oluşturan meslek grupları) açı̆̆a çıkmasını sağlamış. Bu çok aktörlü yapının siyasal mücadeleyi merkez ve yerel ya da hükümet taraftarı ve karşıtı ikiliklerine indirgeyemeyeceği gösterilmiştir. İzmir, güçlü yerel koalisyonu yani siyasi sebeple kent-bölge sayılmıştır. Oysaki ekonomik olarak kent-bölge sayılmak için küresel tedarik zincirinde katma değerli ürün üretimine yani yüksek getiri getiren kültür ve lojistik gibi sektörlere yönelmesi ve bu sektörlerde çalışacak nüfusu kendine çekecek imkânlara sahip olması gerekir (a.g.e., s-127-128).

İkinci olarak Adana-Mersin aksı siyaset ve sermaye birikimi arasındaki ilişkiyi çözümlemek için seçilmiştir. Bu bölgenin özgünlüğü pamuk üretiminin getirdiği toprak mülkiyeti yapısında yatmaktadır. Pamuk üretimi, mevsimlik işçi çalıştırarak kolay örgütlendiği için büyük toprak mülkiyetini mümkün kılmıştır (a.g.e., s.142). Adana merkezli kurulan holdinglerin yatırımlarını bu bölgenin dışına yöneltmesi kentte ekonomik güç kaybına neden olmuş ve bu kayıp halen giderilememiştir. Beyrut limanın patlama sonrasında işlevini yitirmesi Mersin limanın önemini arttırmıştır. Bölgeye havalimanı kurulmasıyla da güçlenecek kargo taşımacılığı bölgedeki ekonomik gelişmişliği ve kent-bölge olmasını sağlayacaktır (a.g.e., s. 153-155).

Üçüncü olarak Konya, ekonomik büyümeyi başarmış ama yereli önceleyen bir kentsel koalisyon kurulamadığı için seçilmiştir. Kentteki hâkim koalisyon yerelin önceliklerini savunmak yerine merkezi hükümetin isteklerinin uygulayıcısı konumundadır. Kent ekonomisini küçük ölçekli, dış ticaret odaklı üretim yapan ve esnek çalışan KOBİler biçimlendirmektedir. Kentin 
dış ticaret fazlası vermesini sağlayan bu yapılar bir üst üretim modeline geçmek için gereken kurumsallaşma, nitelikli iş gücünün kente çekilmesi ve büyük altyapı yatırımları gibi eylemleri engellemektedir. Özetle kentin şimdiki imkânları yarını için kısıt haline gelmekte ve kentteki hâkim korporatist yapı bu ileriye atılımı engellemekte.

Son olarak Van, İran'la kurduğu ticari ve kültürel ilişkiler, Türkiye'nin daha doğusundaki ülkeler için göçün kapısı olması ve Türkiye'nin kendi doğusu için merkez olması gibi çok yönlü işlevleri, yönetişimi zorlaştıran yapısı ve ekonomik potansiyeli sebebiyle analize dahil edilmiştir (a.g.e., s.193). Kentin kalkınması ve kent-bölge olmasındaki engeller; merkezin kayyumlar üzerinden müdahaleleri ve kente merkezin bir güvenlik sorunu olarak bakması olarak sıralanmıştır.

\section{Tartışma ve Sonuç}

Kentlerin Türkiye'si kitabında kurulan ideale göre daha eşitlikçi, kapsayıcı ve demokratik bir Türkiye için kent-bölge olma potansiyeli barındıran kentlerin bir takım yerel ekonomik ve siyasi adımlar atması gerekir. Kentlerin ekonomik gelişmeyi sağlaması için küresel tedarik zincirinde daha katma değerli ürünler üretmesi ve bunları üretecek çalışanların yaşayacağı imkânları sağlaması gerekir. Siyasi olarak ise kentin çıarını savunan kentsel büyüme koalisyonları kurması gerekir. Burada merkeze biçilen rol; yerel kendi faydasına kalkınma ve yatırım planları hazırladıktan sonra bunların uygulayıcısı olmak, yerel koalisyonların güçlenmesine izin vermek ve yereli yıpratacak ekonomik ve siyasi müdahalelerden uzak durmaktır.

Kitapta zaman zaman küresel kapitalizmin kimi kentlerin faydasına kimi kentlerin zararına sonuçlar ürettiği söylense de bu yerelin kurduğu küresel ekonomiyle ilişkilenme idealinin çok gerisinde kalır. Özü eşitsiz olan bir ekonomik rejimde böyle bir idealin ne kadar gerçekleştirilebileceği ve hizmet sektöründe yer alan yaratıcı sınıfın soylulaştırma ve ekonomik eşitsizlik gibi üreteceği (Florida, 2017) sonuçların üzeri örtülür. Ama bu perdelenmenin arkasında neoliberalizm ve otoriter yönetim birlikteliğine karşı yereli güçlü bir aktör ve mücadele cephesi olarak kurmak yatmaktadır.

Kitapta merkezin yerele ekonomik müdahalesini yatırım yapılıp yapılmamasıyla sınırlanmış. Ancak Merkez Bankası'na yapılan müdahaleler gibi ekonomiye siyasi müdahaleler sonucu dövizin ani değişimi Anadolu'daki imalat sanayini olumsuz anlamda etkilemektir. Kitaptaki merkez eleştirisine bu tarz müdahalelerin dâhil edilmesi savlarını güçlendirebilirdi. 
Kentlerin Türkiye'si kitabı vaka analizleri üzerinden kent-bölge tartışmalarını Türkiye'ye verimli bir şekilde taşıyor. Dünya genelindeki kent-bölge tartışmalarına Türkiye örneğinin aktarılması ve var olan teorilerin tekrar gözden geçirilmesi için kitabın İngilizce' ye çevrilmesinin büyük önem kazandığını düşünüyorum.

\section{Kaynakça / References}

Florida, R. (2017). The new urban crisis: How our cities are increasing inequality, deepening segregation and failing the middle class and what we can do about it. New York: Basic Books.

Genç, F., Keyder, Ç., Keyman, E. F. ve Badur, A. K. (2021). Kentlerin Türkiye'si: İmkânlar, sınırlar ve çatışmalar. İstanbul: İletişim Yayınları.

Keyman, F., Keyder, Ç., Genç, F. ve Köse, A. (2017). Kent- Bölge: Yerel kalkınmada yeni dinamikler: Türkiye'nin kentlerinden kentlerin Türkiye'sine. 4 Mayıs 2017 tarihinde https:/turkonfed.org/Files/ContentFile/turkiyeninkentlerinden-kentlerin-turkiyesine.pdf adresinden erişildi.

Mardin, Ş. (1973). Center periphery relation: A key to Turkish politics? Daedalus 102, 169-191.

Neuman, M. ve Hull, A. (2009). The futures of the city region, Regional Studies, 43:6, 777-787.

Scott, A. J. (2000). Global city-regions and the new world system. Unpublished Paper, Department of Policy Studies and Department of Geography, University of California, Los Angeles.

Tekeli, İ. (2016). Dünya'da ve Türkiye'de kent kır karşıtlığı yok olurken yerleşmeler için temsil sorunları ve strateji önerileri. Ankara: İdealkent Yayınları. 